\title{
Determination of carbamate pesticide in food using a biosensor based on reduced graphene oxide and acetylcholinesterase enzyme
}

\author{
Martin K.L. da Silva, Heloísa C. Vanzela, Lucas M. Defavari, Ivana Cesarino* \\ Sao Paulo State University (UNESP), School of Agriculture, Botucatu, SP, Brazil
}

\section{A R T I C L E I N F O}

\section{Keywords:}

Reduced graphene oxide

Carbaryl

Acetylcholinesterase enzyme

Biosensor

Food safety

\begin{abstract}
A B S T R A C T
Food safety is a major concern for human health and wellbeing all over the world. A novel and sensitive biosensor based on reduced graphene oxide (rGO) and the enzyme acetylcholinesterase (AChE) was developed and applied for the detection of carbaryl in food samples. The glassy carbon/rGO/AChE biosensor was characterized morphologically and electrochemically using scanning electron microscopy and cyclic voltammetry/electrochemical impedance spectroscopy, respectively. Optimum differential pulse voltammetry conditions led to a nanomolar detection limit, and determination of carbaryl in tomato was achieved.
\end{abstract}

\section{Introduction}

Carbaryl is an agricultural pesticide from the carbamate class [1]. This pesticide is extensively used in agriculture due to its high insecticidal activity, mostly in tomato, apple, onion and beans [2-5]. Carbamate and organophosphorus pesticides can inhibit acetylcholinesterase (AChE) inhibition; this enzyme is responsible for terminating the transmission of nerve impulses at the synapse [6]. Ingestion of AChE inhibitors might cause several neurological and motorial complications, and might lead to Alzheimer's disease [7]. Currently, the Brazilian Health Regulatory Agency (ANVISA) states a concentration limit for carbaryl of $0.1 \mathrm{mg} / \mathrm{kg}$ for tomato samples and $2.0 \mathrm{mg} / \mathrm{kg}$ for apple. However, monitoring such pollutants is a major challenge.

During the past decades, numerous methodologies have been developed for analysis of pesticides in environmental, food and clinical samples [8]. Among them, colorimetry and chromatography techniques such as gas chromatography and high-performance liquid chromatography have been applied for the detection of these hazardous pollutants [3,9-11]. However, this analysis required matrix treatment, expensive equipment, trained staff for operation, and a great amount of solvents and chemicals. Biosensors based on AChE for the detection of carbamate or organophosphorus pesticides emerged in 1980 to overcome some of the limitations of traditional analysis. In the past two decades, there has been continuous development of biosensors for detection of these pollutants. Membrane [12-14], sol-gel [15-17], quantum-dot [18,19] and nanoparticle-based AChE biosensors [20,21] are the main amperometric/electrochemical biosensors developed in the field.
Developing novel, fast and highly sensitive electrochemical biosensors for pesticides and food safety is a major goal for future electroanalysis [22]. Reduced graphene oxide represents a class of carbonbased materials that have been extensively used in electroanalysis for hormones [23,24], antibiotics [25,26] and biosensing [27,28], due to their high electrocatalytic activity, remarkable electronic transport properties and large surface area [29-32]. The main point of this article is to describe the preparation, characterization and application of an electrochemical biosensor based on reduced graphene oxide for the immobilization of AChE, and its application for carbaryl detection in food samples.

\section{Methodology}

\subsection{Chemicals and solutions}

All solutions were prepared with water purified using a Millipore ultrapure water system with resistivity $\geq 18 \mathrm{M} \Omega \mathrm{cm}$ (Millipore). All reagents used in this study were of analytical grade and were used without further purification. Graphene oxide, AChE from Electrophorus electricus Type VI-S, lyophilized powder, 200-1000 units/mg protein), acetylthiocholine iodide (AChI), carbaryl PESTANAL ${ }^{\circ}$ and glyphosate PESTANAL ${ }^{\oplus}$ were obtained from Sigma-Aldrich (Germany).

\subsection{Electrochemical experiments}

For characterization of the biosensor and analysis of the pesticide, cyclic voltammetry (CV)/electrochemical impedance spectroscopy

\footnotetext{
* Corresponding author at: Rua José Barbosa de Barros, nº 1780, 18.610-307 Botucatu, SP, Brazil.

E-mail address: ivana@fca.unesp.br (I. Cesarino).
} 
(EIS) and differential pulse voltammetry (DPV) procedures, respectively, were performed using an Autolab PGSTAT128 N electrochemical system (Metrohm). All measurements were recorded in NOVA 2.0 software (Metrohm). A conventional three-electrode electrochemical cell was assembled: bare glassy carbon (GC), GC/reduced graphene oxide (rGO), or $\mathrm{GC} / \mathrm{rGO} / \mathrm{AChE}$ as the working electrode (diameter: $3 \mathrm{~mm}) ; \mathrm{Ag} / \mathrm{AgCl} / \mathrm{KCl}\left(3.0 \mathrm{~mol} \mathrm{~L}^{-1}\right)$ as the reference electrode; and a Pt plate as the auxiliary electrode. The experiments were conducted at $25 \pm 1{ }^{\circ} \mathrm{C}$. Electrochemical characterization of the $\mathrm{GC} / \mathrm{rGO} / \mathrm{AChE}$ electrode was performed using $\mathrm{CV}$ in $0.2 \mathrm{~mol} \mathrm{~L}^{-1}$ phosphate buffer solution (PBS) pH 7.0 at a scan rate of $50 \mathrm{mV} \mathrm{s}^{-1}$. The EIS spectra were scanned in the $10^{7}$ to $10^{-2} \mathrm{~Hz}$ frequency range with 10 data points per frequency decade. The impedance spectra were recorded in open circuit potential (OCP) conditions in $0.2 \mathrm{~mol} \mathrm{~L}^{-1} \mathrm{PBS} \mathrm{pH} 7$ containing $5.0 \mathrm{mmol} \mathrm{L}^{-1}$ of $\left[\mathrm{Fe}(\mathrm{CN})_{6}\right]^{3-/ 4-}$. Fitting and calculation to an equivalent electrical circuit, and $R_{\mathrm{ct}}$ values, were performed using the electrochemical circle fit tool in Nova 2.0 software. DPV measurements were obtained at a scan rate of $10 \mathrm{mV} \mathrm{s}^{-1}$, pulse amplitude of $100 \mathrm{mV}$, and a step potential of $5 \mathrm{mV}$ in $0.2 \mathrm{~mol} \mathrm{~L}^{-1} \mathrm{PBS} \mathrm{pH} 7.0$ containing $40.0 \mu \mathrm{mol} \mathrm{L}{ }^{-1}$ of AChI. The surface morphology of the nanocomposites was characterized by scanning electron microscopy (SEM), and the images were recorded using a Quanta 200 microscope (FEI Company, Hillsboro, USA).

\subsection{Synthesis of the reduced graphene oxide}

The rGO synthesis is described extensively elsewhere [28,23]. Concisely, a solution containing $20 \mathrm{mg} \mathrm{GO}, 15.0 \mathrm{ml}$ of ethanol (pure grade) and $16.0 \mathrm{mg}$ of SDS was sonicated for $20 \mathrm{~min}$ in an ultrasonic bath (70\% amplitude). Then, $8.0 \mathrm{mg}$ of $\mathrm{NaBH}_{4}$ was added to the solution, and the suspension was sonicated for a further $20 \mathrm{~min}$. The solution was then centrifuged and cleaned multiple times with pure grade ethanol and ultrapure water. The resultant rGO composite was dried at $60^{\circ} \mathrm{C}$. Finally, the rGO composite was kept at $4{ }^{\circ} \mathrm{C}$ at a concentration of $1.0 \mathrm{mg} \mathrm{mL}^{-1}$.

\subsection{Construction of the $G C / r G O / A C h E$ biosensors}

The GC electrodes were polished with $0.3-\mu \mathrm{m}$ alumina slurry, sonicated for $5 \mathrm{~min}$ in ethanol and $5 \mathrm{~min}$ in ultrapure water, and then dried at room temperature.

For preparation of $\mathrm{GC} / \mathrm{rGO} / \mathrm{AChE}$ biosensors, a solution containing $25.0 \mu \mathrm{g}$ of rGO and $40.0 \mu \mathrm{g}$ of AChE was mixed in an Eppendorf tube. On the surfaces of the cleaned GC electrodes, $10 \mu \mathrm{l}$ of $\mathrm{rGO} / \mathrm{AChE}$ biocomposite was cast and allowed to dry at room temperature.

\subsection{Preparation of the fruit samples for carbaryl analysis}

The developed biosensor was applied for the determination of carbaryl pesticide in tomato samples. Briefly, $200 \mathrm{~g}$ of tomato samples acquired in local markets was blended in a $0.2 \mathrm{~mol} \mathrm{~L}^{-1} \mathrm{PBS}$ solution $\mathrm{pH}$ 7.0. DPV analysis of carbaryl was carried out directly on the extracts of tomato samples using the standard addition method.

\section{Results and discussion}

\subsection{Morphological and electrochemical characterization of the $r G O / A C h E$ biocomposite}

SEM images of rGO and the rGO/AChE biocomposite were prepared by dropping a significant amount of the material onto a silica plate and drying before analysis. Fig. 1 shows SEM images of rGO (A) and rGO/ AChE biocomposite (B), respectively. Fig. 1A reveals that the typical wrinkled structure of rGO displays a large amount of topological defects created by the oxidation-reduction procedure on its surface $[24,25,23]$, proving the reduction of GO by the proposed method. The rGO sheet
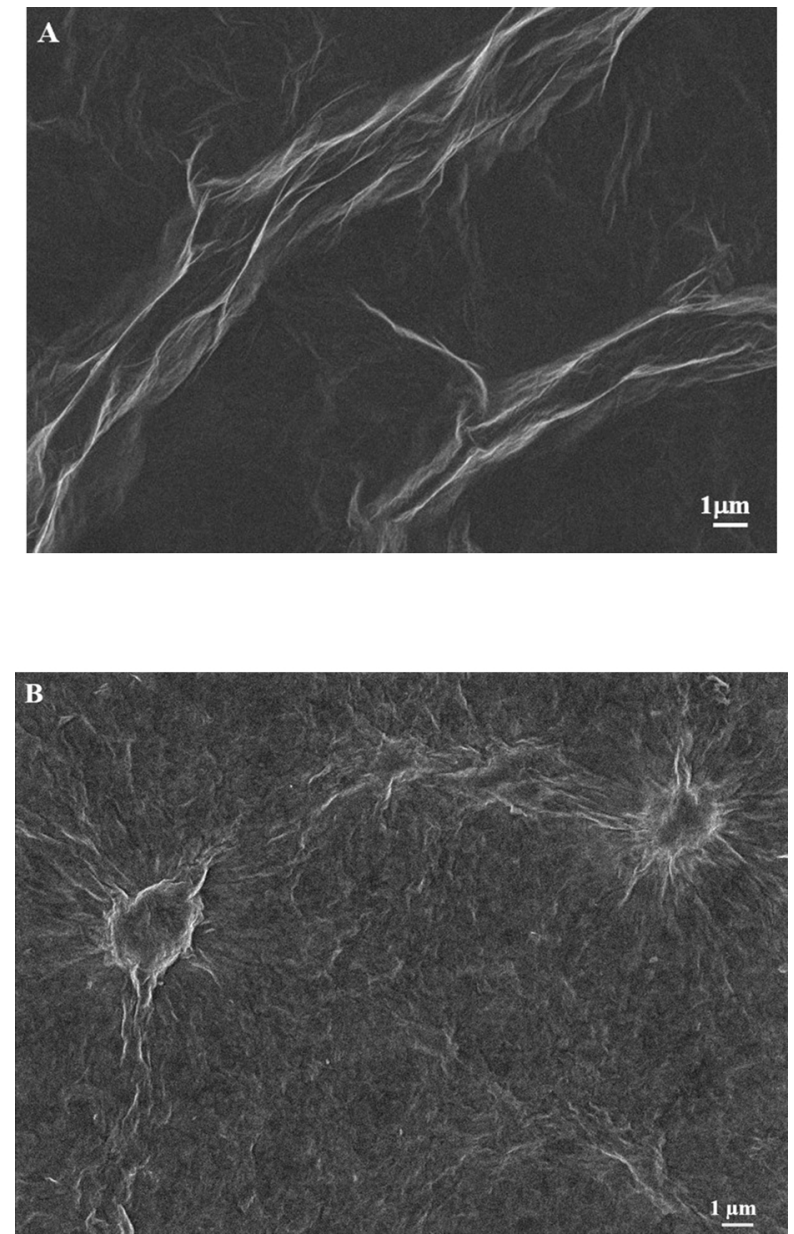

Fig. 1. FEG-SEM micrographs for (A) rGO and (B) rGO/AChE.

morphology shows several clusters of topological defects [33]. In Fig. 1B we can see the immobilization of AChE by rGO structural defects. These clusters can incorporate and immobilize enzymes, providing an excellent material for biosensing measurements since no cross-linking agent is needed [28].

The electrochemical response of the $\mathrm{GC} / \mathrm{rGO} / \mathrm{AChE}$ biosensor was investigated in $0.2 \mathrm{~mol} \mathrm{~L}^{-1}$ of PBS pH 7.0 containing $40.0 \mu \mathrm{mol} \mathrm{L}^{-1}$ of AChI by CV experiments at a scan rate of $50 \mathrm{mV} \mathrm{s}^{-1}$, as presented in Fig. 2. In the absence of AChI (curve a), no electrochemical process was observed. On the other hand, in the presence of AChI (curve b), the proposed biosensor presented oxidation and reduction processes of dithio-bis-choline at potentials of +222 and $+182 \mathrm{mV}$, respectively, with the mechanism shown in the inset of Fig. 2. The reaction of AChE's substrate is a two-step reaction. First, the neurotransmitter acetylcholine is hydrolysed, giving thiocholine and acetic acid as products. The subsequent reaction is the formation of the dimer dithio-bis-choline [6].

EIS is the most used technique for probing biomolecular interactions and the conductivity of modified electrodes and understanding chemical reactions, as well as for the investigation of immunosensors, biosensors and DNA/RNA sensors [34-36]. EIS experiments were conducted to characterize the proposed biosensor. Fig. 3 shows the typical Nyquist plots for GC, GC/GO, GC/rGO and GC/rGO/AChE electrodes in a $0.2 \mathrm{~mol} \mathrm{~L}^{-1} \mathrm{PBS} \mathrm{pH} 7.0$ solution containing $0.1 \mathrm{~mol} \mathrm{~L}^{-1}$ of $\mathrm{KCl}$ and $5 \mathrm{mmol} \mathrm{L}{ }^{-1}$ of the redox couple $[\mathrm{Fe}(\mathrm{CN}) 6]^{3-/ 4-}$ in the range of $0.01-100 \mathrm{kHz}$. The semicircles correspond to the charge transfer resistance $\left(R_{\mathrm{ct}}\right)$ limiting process that is associated with the electrode/ electrolyte interface. It is possible to observe the following order for the $R_{\text {ct }}$ values: $R_{\mathrm{ct}}(\mathrm{GC} / \mathrm{rGO} / \mathrm{AChE})>R_{\mathrm{ct}}(\mathrm{GC} / \mathrm{GO})>R_{\mathrm{ct}}(\mathrm{GC} / \mathrm{rGO})>R_{\mathrm{ct}}$ (GC). As expected, the bare GC electrode presented a very low $R_{\mathrm{ct}}$ 


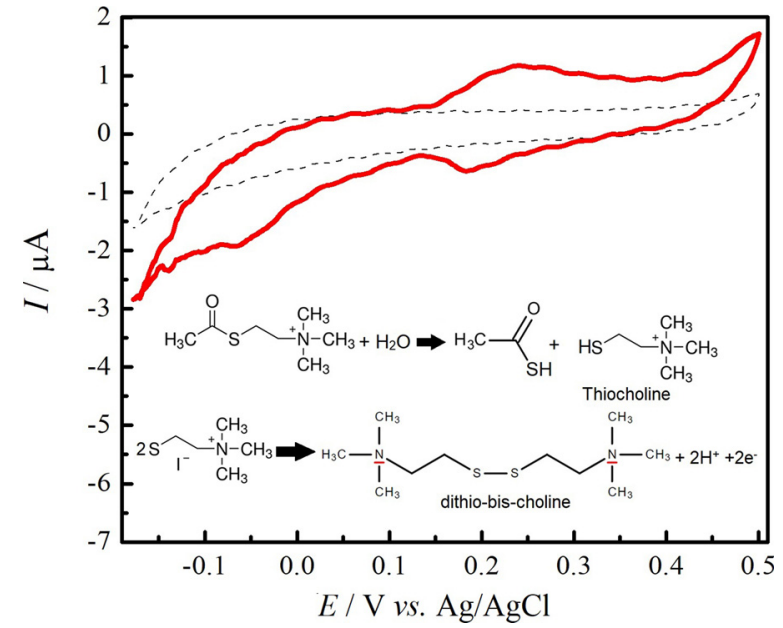

Fig. 2. $\mathrm{CV}$ scans of the $\mathrm{GC} / \mathrm{rGO} / \mathrm{AChE}$ biosensor in $0.2 \mathrm{~mol} \mathrm{~L}^{-1} \mathrm{PBS} \mathrm{pH} 7.0$ in the absence (traced line) and in the presence (solid line) of $40.0 \mu \mathrm{mol} \mathrm{L}^{-1}$ of AChI with a scan rate of $50 \mathrm{mV} \mathrm{s}^{-1}$. Inset: electrochemical process of thiocholine oxidation with the formation of the respective dimer, ditihio-bis-choline.

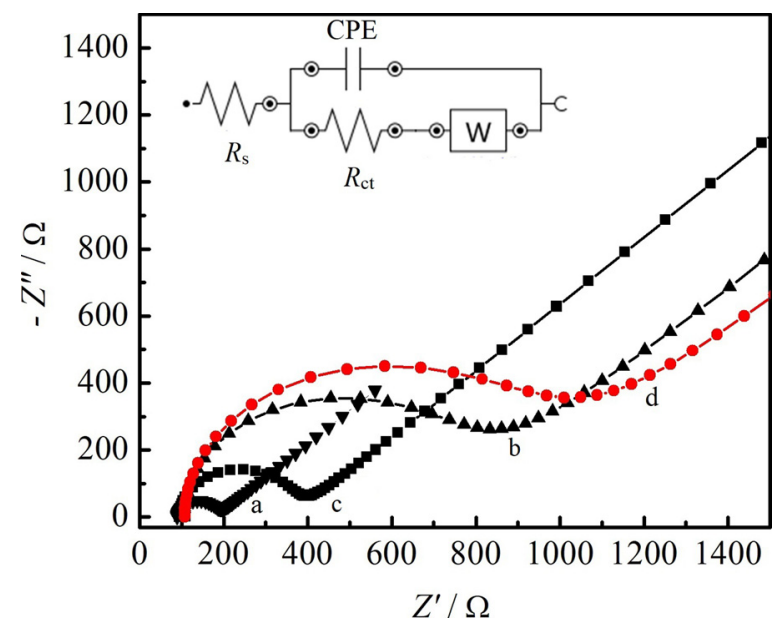

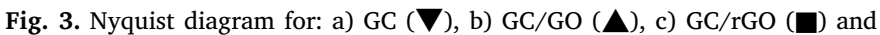
$\mathrm{GC} / \mathrm{rGO} / \mathrm{AChE}(\bullet)$ electrodes recorded in a $0.2 \mathrm{~mol} \mathrm{~L}^{-1} \mathrm{PBS} \mathrm{pH} 7.0$ solution containing $5.0 \mathrm{mmol} \mathrm{L}^{-1}$ of the redox couple $\left[\mathrm{Fe}\left(\mathrm{CN}_{6}\right)\right]^{3-/ 4-}$.

Table 1

Fitting values of the equivalent circuit elements.

\begin{tabular}{llll}
\hline Electrode & $R_{\mathrm{s}}(\Omega)$ & $R_{\mathrm{ct}}(\Omega)$ & $\mathrm{CPE}(\mu \mathrm{S} / \mathrm{cm})$ \\
\hline $\mathrm{GC}$ & 86.4 & 116 & 2.06 \\
$\mathrm{GC} / \mathrm{GO}$ & 84.8 & 853 & 44.7 \\
$\mathrm{GC} / \mathrm{rGO}$ & 68.8 & 665 & 28.4 \\
$\mathrm{GC} / \mathrm{rGO} / \mathrm{AChE}$ & 81.8 & 1120 & 65.8 \\
\hline
\end{tabular}

$(\sim 107.5 \Omega)$ with a close to straight tail line $[37,38]$ (curve a). The GC/ GO electrode (curve b) showed an increase in $R_{\mathrm{ct}}(\sim 852.53 \Omega$ ) due to graphene oxide's insulator property. Otherwise, GC/rGO (curve c) decreases $R_{\mathrm{ct}}$ drastically $(\sim 488.08 \Omega)$; this behaviour is expected due to rGO's extraordinary electron-transfer properties, which can facilitate the diffusion of electrons at the electrode/electrolyte interface [39]. On the other hand, biomolecules such as AChE are poor electrical conductors at low frequencies and can make the electron-transfer process difficult $[3,40]$. The GC/rGO/AChE electrode showed an $R_{\mathrm{ct}}$ value of $\sim 1120 \Omega$, evidence of the successful immobilization of AChE onto the electrode surface. The EIS spectrum for each electrode was fitted using the electrochemical circle fit tool in NOVA 2.0 software, as was the

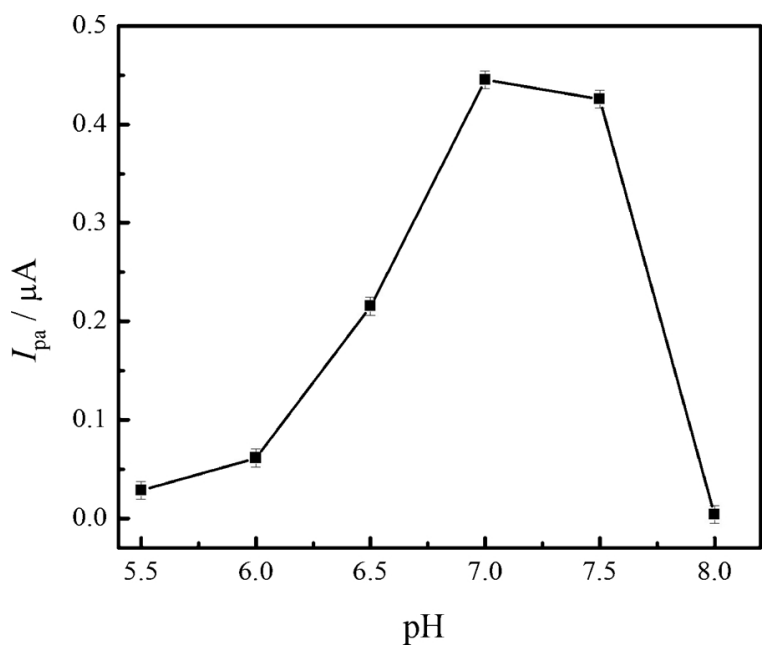

Fig. 4. Effect of $\mathrm{pH}$ on the anodic peak current for thiocholine oxidation for the $\mathrm{GC} / \mathrm{rGO} / \mathrm{AChE}$ biosensor electrode in a $0.2 \mathrm{~mol}^{-1} \mathrm{PBS}$ solution containing $40 \mu \mathrm{mol} \mathrm{L}{ }^{-1}$ of AChI.

equivalent circuit (inset Fig. 3). The fitting values are summarized in Table 1 , including the ohmic resistance of the electrolyte $\left(R_{\mathrm{s}}\right), R_{\mathrm{ct}}$, the constant phase element (CPE) and the Warburg impedance (W).

\subsection{Optimization of the $G C / r G O / A C h E$ biosensor parameters}

To assure the maximum analytical response from the $\mathrm{GC} / \mathrm{rGO} / \mathrm{AChE}$ biosensor electrode, the dependence of the electrochemical oxidation of dithio-bis-choline on $\mathrm{pH}$ was studied by DPV experiments at $\mathrm{pHs}$ ranging from 5.5 to 8.0 in $0.2 \mathrm{~mol} \mathrm{~L}^{-1}$ PBS containing $40.0 \mu \mathrm{mol} \mathrm{L}^{-1} \mathrm{AChI}$, as presented in Fig. 4. The plot of $I_{\mathrm{pa}} v s$. $\mathrm{pH}$ for dithio-bis-choline shows that the anodic peak current increases in the $\mathrm{pH}$ range of 5.5 to 7.0, reaching a maximum value at $\mathrm{pH}$. 7.0 and slightly decreasing at $\mathrm{pH}$ 7.5. As reported, the optimum pH for AChE is 8.0-9.0 [41]; some biosensors based on rGO also report $\mathrm{pH} 7.0$ as an optimum $\mathrm{pH}$ for buffer solution $[42,43]$. Hence, pH 7.0 was chosen for use in subsequent experiments.

Another optimized parameter was the amount of rGO used in the preparation of the biosensor. The quantities of rGO studied were 12.5, 25.0, 50.0, 75.0 and $100.0 \mu \mathrm{g} \mathrm{mL}^{-1}$ with $40.0 \mu \mathrm{g}$ of AChE; the results are presented in Fig. 5A. The highest anodic peak current was observed when $10 \mu \mathrm{l}$ of a suspension containing $25 \mu \mathrm{g} \mathrm{m}^{-1}$ of rGO was used in the preparation of the biosensor. An increase of the composite material can block the electron-transfer process through the electrode/electrolyte interface, in that way decreasing the response for AChI substrate. Therefore, this amount of the composite was used in further experiments.

Another important aspect for preparation of the biosensor is the amount of AChE. The concentration of AChE in the composition of the biosensor was optimized in the range of $5.0-80.0 \mu \mathrm{gL}^{-1}$ in $0.2 \mathrm{~mol}$ $\mathrm{L}^{-1}$ of PBS pH 7.0 containing $40.0 \mu \mathrm{mol} \mathrm{L}^{-1}$ of AChI; the results are presented in Fig. 5B. It is possible to observe that the anodic peak current increases considerably up to the amount of $40.0 \mu \mathrm{g} \mathrm{mL} \mathrm{L}^{-1}$ of $\mathrm{AChE}$ and decreases when a higher concentration of enzyme is used in the preparation of the biocomposite. This behaviour is common for biosensors; a small amount of AChE cannot hydrolyse and catalyse AChI entirely. On the other hand, at higher concentrations, the AChE electron transfer between substrate and electrode is affected negatively, as biomolecules are poor electrical conductors, which can inhibit the anodic response for AChI. Therefore, $40.0 \mu \mathrm{g} \mathrm{mL}^{-1}$ of AChE enzyme was used in the preparation of the biosensor for the next experiments.

\subsection{Analytical curve}

For evaluation of the $\mathrm{GC} / \mathrm{rGO} / \mathrm{AChE}$ biosensor for the detection of 

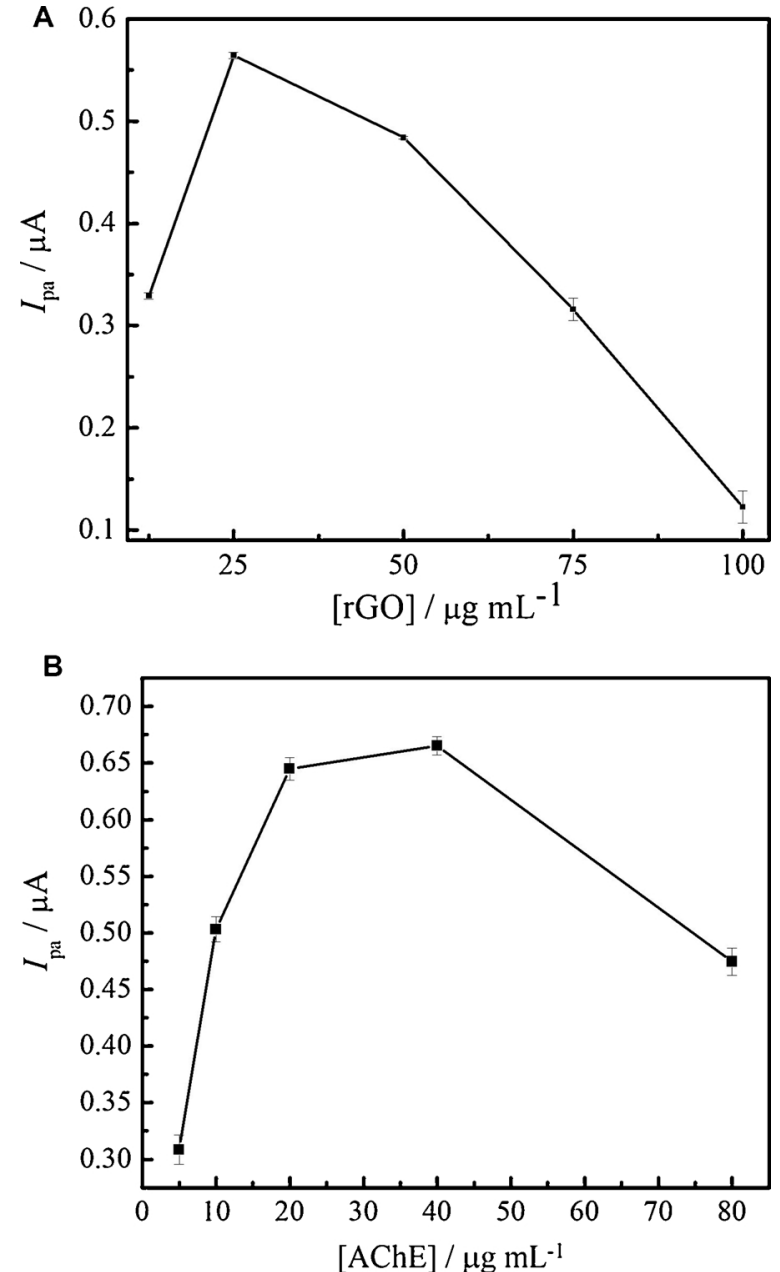

Fig. 5. Optimization of the biosensor composition using DPV in $0.2 \mathrm{~mol} \mathrm{~L}^{-1}$ PBS pH 7.0 in the presence of $40.0 \mu \mathrm{mol} \mathrm{L}^{-1}$ of AChI: A) Influence of the amount of the $\mathrm{rGO}$ and $\mathrm{B}$ ) Influence of AChE enzyme concentration.

carbamate pesticide, DPV voltammograms were recorded in the absence and presence of different carbaryl concentrations, as presented in Fig. 6. We observed a linear response to the inhibition of the thiocholine oxidation process for carbaryl concentrations from 10 to $50 \mathrm{nmol}$ $\mathrm{L}^{-1}$ (Fig. 6A) and 0.2 to $1.0 \mu \mathrm{mol} \mathrm{L}{ }^{-1}$ (Fig. 6B), according to Eqs. (1) and (2), respectively:

$$
\begin{aligned}
& I(\%)=12.27+1.98 \text { [carbaryl] } \\
& I(\%)=53.29+40.17 \text { [carbaryl] }
\end{aligned}
$$

with correlation coefficients of $0.997(n=5)$ and $0.988(n=5)$ for Eqs. (1) and (2), respectively. Inhibition of the thiocholine signal was calculated using the peak currents of the thiocholine before $\left(I_{0}\right)$ and after $\left(I_{1}\right)$ incubation with carbaryl, as described elsewhere [44]. Using the first equation, a detection limit (LOD) of $1.9 \mathrm{nmol} \mathrm{L}^{-1}$ was calculated by $3 \sigma /$ slope, where $\sigma$ is the standard deviation of 10 current-time measurements of the blank solution. Also, the quantification limit (LOQ) of $6.3 \mathrm{nmol} \mathrm{L}^{-1}$ was determined by $10 \sigma /$ slope, as recommended by IUPAC methodology [45].

Table 2 shows the comparison of different biosensors and their LOD values. Cesarino et al. [46,47] used an electropolymerization polyaniline film for AChE immobilization on carbon nanotubes. An AChE-epGON/GCE was applied for the detection of carbaryl by Li et al. [37]. In addition, multiwall carbon nanotubes/graphene oxide nanoribbons [38] and gold electrodes [48] were applied for immobilization of AChE and used as a biosensor for pesticides. We can observe that the GC/
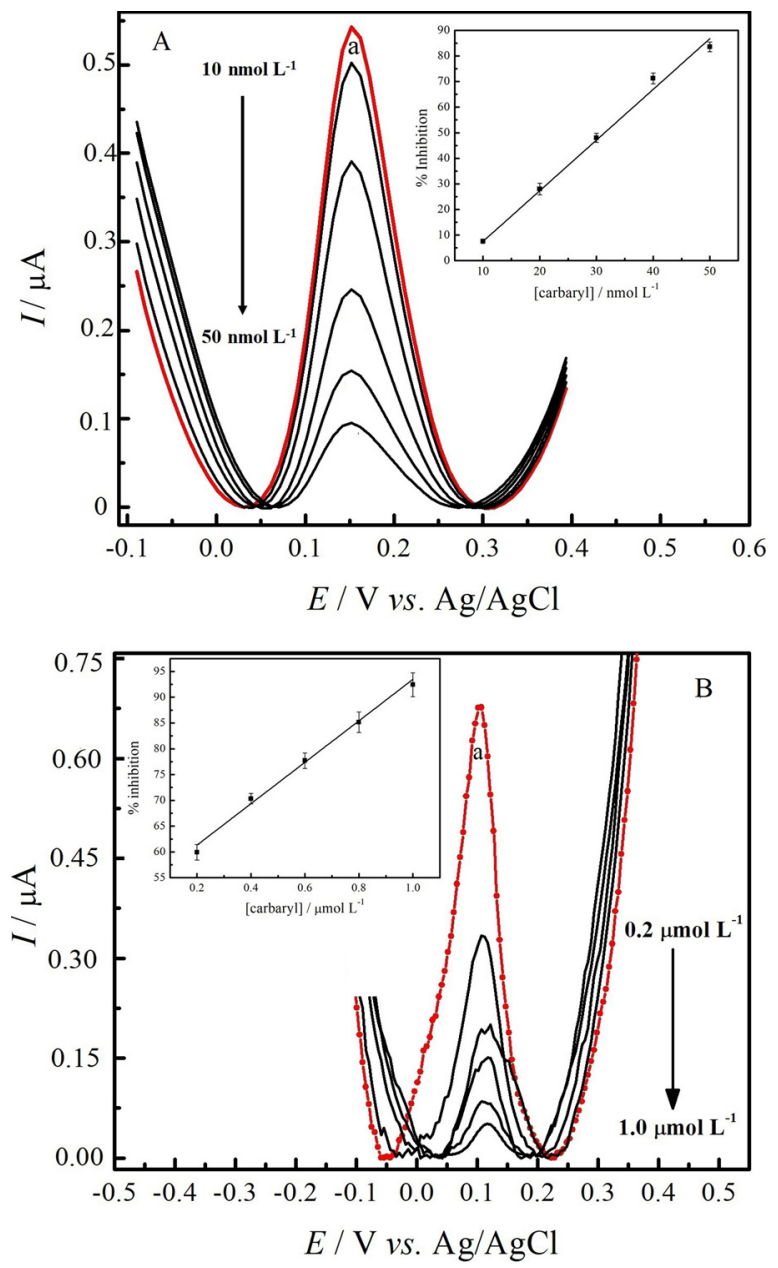

Fig. 6. DPV voltammograms for $\mathrm{GC} / \mathrm{rGO} / \mathrm{AChE}$ biosensor electrode in the absence (a) and in the presence of A) $10-50 \mathrm{nmol} \mathrm{L}^{-1}$ of carbaryl and B) $0.2-1.0$ $\mu \mathrm{mol} \mathrm{L}{ }^{-1}$ of carbaryl. Inset: linear dependence of the enzyme inhibition with carbaryl concentrations.

Table 2

Limit of detection comparison of different biosensors in the determination of Carbaryl pesticide. MPA: mercaptopropionic acid; ChO: cholineoxidase; PANI: polyaniline; MWCNT: multiwall carbon nanotubes; GONRs: graphene oxide nanoribbons nanostructure; e-pGON: electrochemically inducing porous graphene oxide network.

\begin{tabular}{lll}
\hline Biosensor & LOD $\left(\mathrm{nmol} \mathrm{L}^{-1}\right)$ & Ref. \\
\hline Au-MPA-AChE/ChO SAM & 5.96 & {$[48]$} \\
GC/MWCNT/PANI/AChE & 5 & {$[47]$} \\
GC/rGO/AChE & 1.9 & This work \\
AChE-MWCNTs/GONRs/GCE & 1.7 & {$[38]$} \\
AChE-e-pGON/GCE & 0.79 & {$[37]$} \\
\hline
\end{tabular}

rGO/AChE biosensor has the lowest LOD for carbaryl, except for the biosensor in the work presented by Li et al. [37]. The biosensor showed a very similar LOD to that in the work presented by Qiu et al. [17] who developed an AChE-MWCNT/GONR/GCE biosensor. However, the biosensor presented in this work showed good linearity, reproducibility and selectivity for carbaryl pesticide.

The repeatability of $1.3 \%$ for the proposed biosensor was evaluated by measuring the current response of $10 \mathrm{DPV}$ voltammograms after $5 \mathrm{~min}$ of incubation in $0.2 \mu \mathrm{mol} \mathrm{L}{ }^{-1}$ carbaryl solution. The reproducibility of $2.2 \%$ was determined by the standard deviation of 10 sequential voltammograms from five experiments [23]. The favourable electron-transfer kinetics and high sensitivity originate from the good 


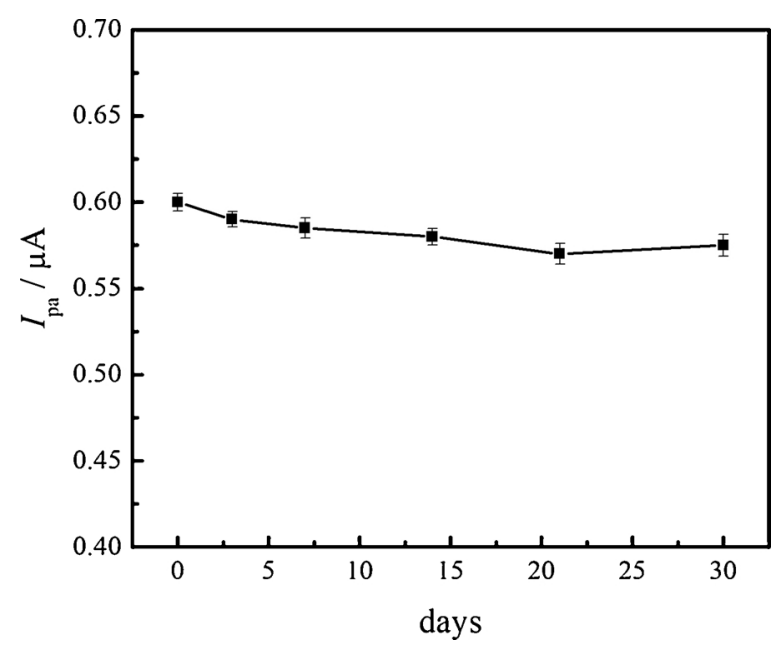

Fig. 7. Lifetime of the GC/rGO/AChE biosensor.

conductivity and large surface area of rGO favouring immobilization of enzymes [49].

The lifetime of the proposed biosensor was evaluated by DPV experiments in the presence of $40.0 \mu \mathrm{mol} \mathrm{L}{ }^{-1}$ of AChI. The results are presented in Fig. 7. The GC/rGO/AChE biosensor showed almost the same response for thiocholine oxidation at 3, 7, 14, 21 and 30 days. During the measurements, the biosensor was kept in $0.2 \mathrm{~mol} \mathrm{~L}^{-1} \mathrm{PBS}$ $\mathrm{pH} 7.0$ at $4{ }^{\circ} \mathrm{C}$. As no significant change in the electrochemical response for thiocholine oxidation was observed, the biosensor can be applied within 30 days. The longer lifetime for the biosensor is due to the high stability and longer lifetime of rGO than for other similar commercial sensors. Large surface area, fast response time, lower potential for redox reactions and fewer surface fouling effects have brought attention to graphene-based biosensors [49].

\subsection{Interferents and selectivity studies for the $G C / r G O / A C h E$ biosensor facing glyphosate pesticide}

In order to evaluate interference in the presence of other compounds and the selectivity of the proposed biosensor, DPV experiments were carried out by the following procedure. Firstly, the response to a $40.0 \mu \mathrm{mol} \mathrm{L}^{-1} \mathrm{AChI}$ aliquot was recorded, then the biosensor was incubated for $5 \mathrm{~min}$ in a PBS $\mathrm{pH} 7.0$ solution containing $0.2 \mu \mathrm{mol} \mathrm{L} \mathrm{L}^{-1}$ carbaryl. After this first step, the biosensor was incubated for $5 \mathrm{~min}$ in a PBS solution with $0.1,0.2$ and $0.4 \mu \mathrm{mol} \mathrm{L}^{-1}$ of glyphosate. The results are shown in Fig. 8.

We observed that the biosensor showed an impressive selectivity for carbaryl pesticide. The carbamate pesticide exclusively inhibited the dithio-bis-choline oxidation process. On the other hand, when analysing various concentrations of glyphosate, the biosensor showed a stable response and no significant change in the thiocholine oxidation process. Since glyphosate does not inhibit AChE enzyme activity, this result was expected. This analyte is not an organophosphate ester but a phosphanoglycine [50].

\subsection{Analysis of carbaryl in the tomato samples}

The developed biosensor was used for the quantification of carbaryl in tomato samples acquired locally. Carbaryl determinations were performed in triplicate, without any further spiking procedure, using the standard addition method; these showed a good response and linearity. However, the matrix effect of the tomato samples dislocated the anodic peak current response of thiocholine. According to Fig. 9, we can observe that the oxidation of thiocholine was dislocated from 128 to $\sim 219 \mathrm{mV}$. However, the addition of carbaryl could be performed easily, and no significant change in the determined concentration of

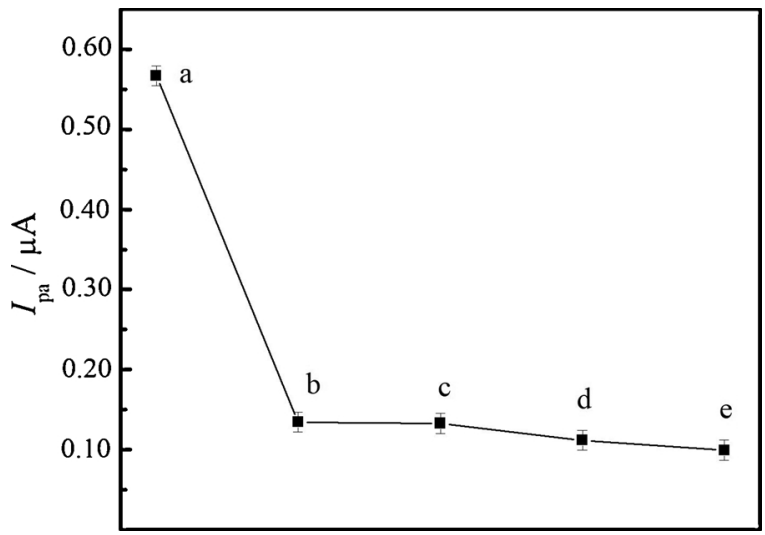

Fig. 8. DPV responses obtained on a $\mathrm{GC} / \mathrm{rGO} / \mathrm{AChE}$ biosensor for the detection of carbaryl pesticide in tomato samples: a) blank $-40.0 \mu \mathrm{mol} \mathrm{L} \mathrm{L}^{-1}$ AChI; b) incubation for $5 \mathrm{~min}$ in the tomato sample; c) addition of $0.1 \mu \mathrm{mol} \mathrm{L}{ }^{-1}$ carbaryl; d) addition of $0.2 \mu \mathrm{mol} \mathrm{L}{ }^{-1}$ carbaryl and e) addition of $0.3 \mu \mathrm{mol} \mathrm{L}^{-1}$ carbaryl. Inset: linear dependence of the inhibition of thiocholine process with carbaryl concentrations.

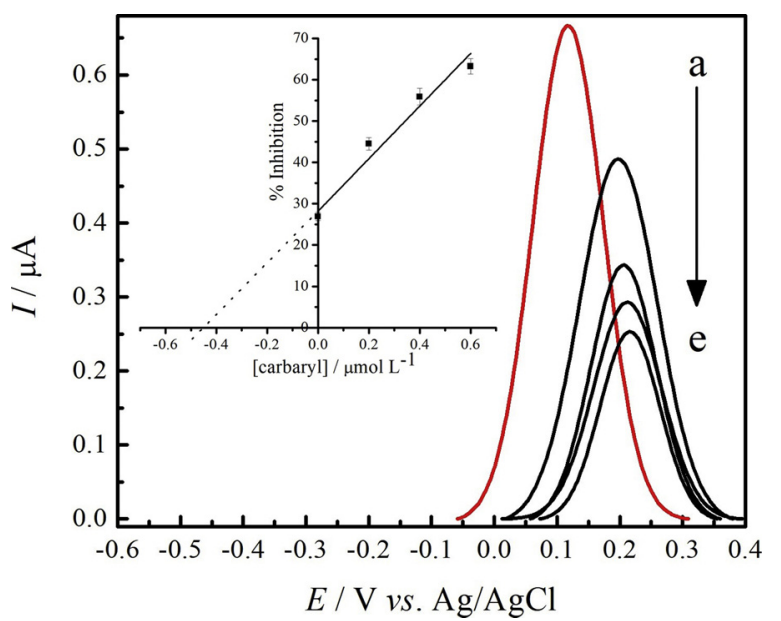

Fig. 9. Effect of glyphosate pesticide as interferents on the response to (a) $40.0 \mu \mathrm{mol} \mathrm{L}{ }^{-1}$ AChI, (b) in the presense of $0.2 \mu \mathrm{mol} \mathrm{L}^{-1}$ of carbaryl and after incubation for $5 \mathrm{~min}$ in (c) 0.1 , (d) 0.2 and (e) $0.4 \mu \mathrm{mol} \mathrm{L}{ }^{-1}$ of glyphosate.

carbaryl was noted. The determination of carbaryl in tomato samples was performed in triplicate, with a mean value of $0.47 \pm 0.04 \mu \mathrm{mol}$ $\mathrm{L}^{-1}$ which is very close to the residual limit of carbaryl in tomato,

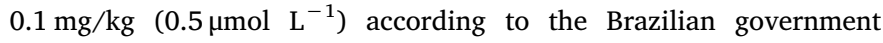
$[2,44]$.

\section{Conclusion}

The electrochemical biosensor based on chemically reduced graphene oxide and AChE enzyme was successfully applied for the determination of carbaryl in tomato samples. The present work contributes to the field of biosensors and provides a novel tool for monitoring carbamate pesticides in food samples. SEM images and CV and IES experiments showed that AChE was efficiently immobilized on the rGO surface, providing a low-cost sensor for pesticide analysis.

\section{Acknowledgements}

The authors would like to acknowledge the financial supportof FAPESP (grant 2015/02136-2) and the LMA-IQ for FEG-SEM facilities. 


\section{References}

1] M.P.R. Lima, D.N. Cardoso, A.M.V.M. Soares, S. Loureiro, Carbaryl toxicity prediction to soil organisms under high and low temperature regimes, Ecotoxicol. Environ. Saf. 114 (2015) 263-272.

[2] ANVISA, Agência Nacional de Vigilância Sanitária, Consult. Pública $\mathrm{N}^{\circ} 66.27$ de outu, (2004) (Accessed 05 February 2018), http://www4.anvisa.gov.br/base/ visadoc/CP/CP [8643-1-0].PDF.

[3] C.S. Pundir, N. Chauhan, Acetylcholinesterase inhibition-based biosensors for pesticide determination: a review, Anal. Biochem. 429 (2012) 19-31.

[4] F. Arduini, F. Ricci, C.S. Tuta, D. Moscone, A. Amine, G. Palleschi, Detection of carbamic and organophosphorous pesticides in water samples using a cholinesterase biosensor based on Prussian Blue-modified screen-printed electrode, Anal. Chim. Acta 580 (2006) 155-162.

[5] B. Li, Y. He, C. Xu, Simultaneous determination of three organophosphorus pesticides residues in vegetables using continuous-flow chemiluminescence with artificial neural network calibration, Talanta 72 (2007) 223-230.

[6] M.B. Olovi, D.Z. Krsti, T.D. Lazarevi-Pati, A.M. Bondi, V.M. Vasi, Acetylcholinesterase inhibitors: pharmacology and toxicology, Curr. Neuropharmacol. 11 (2013) 315-335 (Accessed 30 January 2018), https://www. ncbi.nlm.nih.gov/pmc/articles/PMC3648782/pdf/CN-11-315.pdf.

[7] B.M. McGleenon, K.B. Dynan, A.P. Passmore, Acetylcholinesterase inhibitors in Alzheimer's disease, Br. J. Clin. Pharmacol. 48 (1999) 471-480.

[8] J.J. Vreuls, R.J. Swen, V.P. Goudriaan, M.A. Kerkhoff, G.A. Jongenotter, U.A. Brinkman, Automated on-line gel permeation chromatography-gas chromatography for the determination of organophosphorus pesticides in olive oil, J. Chromatogr. A 750 (1996) 275-286 (Accessed 11 April 2018), http://www.ncbi. nlm.nih.gov/pubmed/8938390.

[9] G.L. Ellman, K.D. Courtney, V. Andres, R.M. Featherstone, A new and rapid colorimetric determination of acetylcholinesterase activity, Biochem. Pharmacol. 7 (1961) 88-95.

[10] H. Mitobe, T. Ibaraki, A. Tanabe, K. Kawata, A. Yasuhara, High performance liquid chromatographic determination of pesticides in soluble phase and suspended phase in river water, Toxicol. Environ. Chem. 81 (2001) 97-110.

[11] S. Kumaran, C. Tran-Minh, Determination of organophosphorous and carbamate insecticides by flow injection analysis, Anal. Biochem. 200 (1992) 187-194 (Accessed 11 April 2018), http://www.ncbi.nlm.nih.gov/pubmed/1595894.

[12] J.-L. Marty, N. Mionetto, T. Noguer, F. Ortega, C. Roux, Enzyme sensors for the detection of pesticides, Biosens. Bioelectron. 8 (1993) 273-280.

[13] V.G. Andreou, Y.D. Clonis, A portable fiber-optic pesticide biosensor based on immobilized cholinesterase and sol-gel entrapped bromcresol purple for in-field use, Biosens. Bioelectron. 17 (2002) 61-69.

[14] T. Shimomura, T. Itoh, T. Sumiya, F. Mizukami, M. Ono, Amperometric biosensor based on enzymes immobilized in hybrid mesoporous membranes for the determination of acetylcholine, Enzyme Microb. Technol. 45 (2009) 443-448.

[15] A.N. Diaz, M.C. Ramos Peinado, Sol-gel cholinesterase biosensor for organophosphonus pesticide fluorimetric analysis, Sens. Actuators B (1997) 38-39 (Accessed 11 April 2018), http://www.biblioteca.uma.es/bbldoc/articulos/16719748.pdf.

[16] K. Anitha, S.V. Mohan, S.J. Reddy, Development of acetylcholinesterase silica sol-gel immobilized biosensor-an application towards oxydemeton methyl detection, Biosens. Bioelectron. 20 (2004) 848-856.

[17] H. Zejli, J.L. Hidalgo-Hidalgo de Cisneros, I. Naranjo-Rodriguez, B. Liu, K.R. Temsamani, J.-L. Marty, Alumina sol-gel/sonogel-carbon electrode based on acetylcholinesterase for detection of organophosphorus pesticides, Talanta 77 (2008) 217-221.

[18] Z. Zheng, Y. Zhou, X. Li, S. Liu, Z. Tang, Highly-sensitive organophosphorous pesticide biosensors based on nanostructured films of acetylcholinesterase and CdTe quantum dots, Biosens. Bioelectron. 26 (2011) 3081-3085.

[19] D. Du, S. Chen, D. Song, H. Li, X. Chen, Development of acetylcholinesterase biosensor based on CdTe quantum dots/gold nanoparticles modified chitosan microspheres interface, Biosens. Bioelectron. 24 (2008) 475-479.

[20] K. Wang, H.-N. Li, J. Wu, C. Ju, J.-J. Yan, Q. Liu, B. Qiu, TiO2-decorated graphene nanohybrids for fabricating an amperometric acetylcholinesterase biosensor, Analyst 136 (2011) 3349.

[21] K. Wang, Q. Liu, L. Dai, J. Yan, C. Ju, B. Qiu, X. Wu, A highly sensitive and rapid organophosphate biosensor based on enhancement of CdS-decorated graphene nanocomposite, Anal. Chim. Acta 695 (2011) 84-88.

[22] I. Cesarino, H.V. Galesco, F.C. Moraes, M.R.V. Lanza, S.A.S. Machado, Biosensor based on electrocodeposition of carbon nanotubes/polypyrrole/laccase for neurotransmitter detection, Electroanalysis 25 (2013) 394-400.

[23] C.A. Donini, M.K.L. da Silva, R.P. Simões, I. Cesarino, Reduced graphene oxide modified with silver nanoparticles for the electrochemical detection of estriol, J. Electroanal. Chem. 809 (2018) 67-73.

[24] I. Cesarino, F.H. Cincotto, S.A.S.S. Machado, A synergistic combination of reduced graphene oxide and antimony nanoparticles for estriol hormone detection, Sens. Actuators B 210 (2015) 453-459.

[25] I. Cesarino, R.P. Simões, F.C. Lavarda, A. Batagin-Neto, Electrochemical oxidation of sulfamethazine on a glassy carbon electrode modified with graphene and gold nanoparticles, Electrochim. Acta 192 (2016) 8-14.

[26] D.L.C. Golinelli, S.A.S. Machado, I. Cesarino, Synthesis of silver nanoparticle-graphene composites for electroanalysis applications using chemical and electrochemical methods, Electroanalysis (2017) 1014-1021.

[27] A.T. Lawal, Progress in utilisation of graphene for electrochemical biosensors, Biosens. Bioelectron. 106 (2018) 149-178.

[28] N.A. Kohori, M.K.L. da Silva, I. Cesarino, Evaluation of graphene oxide and reduced graphene oxide in the immobilization of laccase enzyme and its application in the determination of dopamine, J. Solid State Electrochem. 22 (2018) 141-148.

[29] M. Li, C. Liu, Y. Xie, H. Cao, H. Zhao, Y. Zhang, The evolution of surface charge on graphene oxide during the reduction and its application in electroanalysis, Carbon 66 (2014) 302-311.

[30] C. Gao, X.-J. Huang, Voltammetric determination of mercury(II), TrAC Trends Anal Chem. 51 (2013) 1-12.

[31] A. Thakur, S. Kumar, V.S. Rangra, Synthesis of Reduced Graphene Oxide (rGO) via Chemical Reduction, (2015) p. 80032.

[32] S.J. Rowley-Neale, E.P. Randviir, A.S. Abo Dena, C.E. Banks, An overview of recent applications of reduced graphene oxide as a basis of electroanalytical sensing platforms, Appl. Mater. Today 10 (2018) 218-226.

[33] C. Gómez-Navarro, J.C. Meyer, R.S. Sundaram, A. Chuvilin, S. Kurasch, M. Burghard, K. Kern, U. Kaiser, Atomic structure of reduced graphene oxide, Nano Lett. 10 (2010) 1144-1148.

[34] E. Katz, I. Willner, Probing biomolecular interactions at conductive and semiconductive surfaces by impedance spectroscopy: routes to impedimetric immunosensors, DNA-sensors, and enzyme biosensors, Electroanalysis 15 (2003) 913-947.

[35] S.-M. Park, J.-S. Yoo, Peer reviewed: electrochemical impedance spectroscopy for better electrochemical measurements, Anal. Chem. 75 (2003) 455 A-461 A.

[36] M.I. Prodromidis, Impedimetric immunosensors-a review, Electrochim. Acta 55 (2010) 4227-4233.

[37] Y. Li, L. Shi, G. Han, Y. Xiao, W. Zhou, Electrochemical biosensing of carbaryl based on acetylcholinesterase immobilized onto electrochemically inducing porous graphene oxide network, Sens. Actuators B 238 (2017) 945-953.

[38] Q. Liu, A. Fei, J. Huan, H. Mao, K. Wang, Effective amperometric biosensor for carbaryl detection based on covalent immobilization acetylcholinesterase on multiwall carbon nanotubes/graphene oxide nanoribbons nanostructure, J. Electroanal. Chem. 740 (2015) 8-13.

[39] E. Casero, A.M. Parra-Alfambra, M.D. Petit-Domínguez, F. Pariente, E. Lorenzo, C. Alonso, Differentiation between graphene oxide and reduced graphene by electrochemical impedance spectroscopy (EIS), Electrochem. Commun. 20 (2012) 63-66.

[40] N. Chauhan, J. Narang, C.S. Pundir, Immobilization of rat brain acetylcholinesterase on $\mathrm{ZnS}$ and poly(indole-5-carboxylic acid) modified Au electrode for detection of organophosphorus insecticides, Biosens. Bioelectron. 29 (2011) $82-88$.

[41] X. Wu, X. Zhong, Y. Chai, R. Yuan, Electrochemiluminescence acetylcholine biosensor based on biofunctional AMs-AChE-ChO biocomposite and electrodeposited graphene-Au-chitosan nanocomposite, Electrochim. Acta 147 (2014) 735-742.

[42] N.K. Mogha, V. Sahu, M. Sharma, R.K. Sharma, D.T. Masram, Biocompatible ZrO2 reduced graphene oxide immobilized AChE biosensor for chlorpyrifos detection, Mater. Des. 111 (2016) 312-320.

[43] H.-F. Cui, W.-W. Wu, M.-M. Li, X. Song, Y. Lv, T.-T. Zhang, A highly stable acetylcholinesterase biosensor based on chitosan-TiO2-graphene nanocomposites for detection of organophosphate pesticides, Biosens. Bioelectron. 99 (2018) 223-229.

[44] J. Caetano, S.A.S. Machado, Determination of carbaryl in tomato "in natura" using an amperometric biosensor based on the inhibition of acetylcholinesterase activity, Sens. Actuators B 129 (2008) 40-46.

[45] R. Blanc, A. González-Casado, A. Navalón, J.L. Vílchez, On the estimate of blanks in differential pulse voltammetric techniques: application to detection limits evaluation as recommended by IUPAC, Anal. Chim. Acta 403 (2000) 117-123.

[46] I. Cesarino, F.C. Moraes, M.R.V. Lanza, S.A.S. MacHado, Electrochemical detection of carbamate pesticides in fruit and vegetables with a biosensor based on acetylcholinesterase immobilised on a composite of polyaniline-carbon nanotubes, Food Chem. 135 (2012) 873-879.

[47] I. Cesarino, F.C. Moraes, S.A.S. Machado, A biosensor based on polyaniline-carbon nanotube core-shell for electrochemical detection of pesticides, Electroanalysis 23 (2011) 2586-2593.

[48] A. Hatefi-Mehrjardi, Bienzyme self-assembled monolayer on gold electrode: an amperometric biosensor for carbaryl determination, Electrochim. Acta 114 (2013) 394-402.

[49] Y. Song, Y. Luo, C. Zhu, H. Li, D. Du, Y. Lin, Recent advances in electrochemical biosensors based on graphene two-dimensional nanomaterials, Biosens. Bioelectron. 76 (2016) 195-212.

[50] J. Malik, G. Barry, G. Kishore, The herbicide glyphosate, Biofactors 2 (1989) 17-25 (Accessed 11 January 2018), http://www.ncbi.nlm.nih.gov/pubmed/2679650.

Martin Kássio Leme da Silva received his B.Sc. degree in Chemistry from Sao Paulo State University, Brazil, in 2017. Currently, is a master student in the Biotechnology. He has experience in analytical chemistry, with emphasis on electroanalysis, acting on the following topics: electrochemical sensor and biosensor, modified electrode, graphene, metal nanoparticles and enzymes. Supervisor at Laboratory of Electroanalysis and Nanotechnology (LEN)

Heloísa Catharenussi Vanzela undergraduate student of Bioprocesses and Biotechnology Engineering at Sao Paulo State University. Since 2015, has developed works in electroanalytical chemistry at Laboratory of Electroanalysis and Nanotechnology (LEN).

Lucas Menezes Defavari undergraduate student of Bioprocesses and Biotechnology Engineering at Sao Paulo State University. Since 2015, has developed works in electroanalytical chemistry at Laboratory of Electroanalysis and Nanotechnology (LEN). 
Ivana Cesarino received her B.Sc. degree in Chemistry from Sao Paulo State University, Brazil, in 2003, and Ph.D. in 2009 in Analytical Chemistry from Sao Paulo University, in Brazil. She has been admitted in 2014 as assistant professor at Sao Paulo State University, School of Agriculture. The research areas of interest are related with electroanalysis, mainly, on development and characterization of sensors and biosensors for analysis of environmental and biological interest samples. Head-leader of Laboratory of Electroanalysis and Nanotechnology (LEN). She has published 53 articles and more than 50 participations in conferences. She is a member of the Sociedad Iberoamericana de Electroquímica (SIBAE). 